\title{
The Phenomenology of Attitudes and the Salience of Rational Role and Determination
}

\author{
Fabian Dorsch ${ }^{*}$ \\ Department of Philosophy, University of Fribourg, Switzerland
}

Forthcoming in: Philosophical Explorations, 2016.

\begin{abstract}
The recent debate on cognitive phenomenology has largely focused on phenomenal aspects connected to the content of thoughts. By contrasts, aspects pertaining to their attitude have often been neglected, despite the fact that they are distinctive of the mental kind of thought concerned and, moreover, also present in experiences and thus less contentious than purely cognitive aspects. My main goal is to identify two central and closely related aspects of attitude that are phenomenologically salient and shared by thoughts with experiences, namely the rational role that they play in our mental lives and their determination by factors external to them, such as external objects or reasons. In particular, I aim to defend Phenomenal Rationalism about judgemental thoughts and perceptual experiences: the view that their phenomenal character reflects their rational role, that is, their capacity to provide and/or respond to reasons. I conclude with some remarks about how this view may be extended to other kinds of thought and experience; and about how the phenomenological salience of the specific rational role of individual judgemental thoughts may in fact be used to formulate also an argument for the phenomenological salience of their particular propositional contents.
\end{abstract}

Keywords: judgement; perception; thought; experience; belief; attitude; cognitive phenomenology; phenomenal character; determination; rational role; reasons

\section{Introduction}

The focus of the recent debate on cognitive phenomenology has been primarily on the question of whether the content of thoughts (i.e. how they present things as being) is phenomenologically salient. In particular, it has been asked whether it makes a phenomenal difference which propositions are thought, and which concepts employed. ${ }^{1}$ By contrasts, the issue of whether the attitude of thoughts (i.e. which stance or standpoint they adopt towards their content) is phenomenologically salient is often neglected. ${ }^{2}$ This is surprising for at least two reasons.

One is that the attitudinal aspects of thoughts are more significant and fundamental than the presentational ones. For while attitudinal aspects pertain to the general kind of thought or mental episode at issue (e.g. whether it is a judgemental or an imaginative thought, say), the presentational aspects concern only specific differences among instances of one kind of thought or episode (e.g. whether a given judgement is about a green tree or about a red planet).

The other reason arises from the fact that attitudinal aspects are not only involved in intellectual thoughts, but also in sensory experiences. ${ }^{3}$ For instance, while perceptual experiences present their objects as being part of our actual environment and also purport to present them as 
they really are, imaginative experiences do neither. ${ }^{4}$ If perceptual experiences fail to be veridical, there is something wrong with them. The same is typically not true of imaginative experiences. ${ }^{5}$ This shows that thoughts and experiences may share exactly the same attitudinal aspects. In particular, both may be concerned with reality (in the case of perception, episodic memory or judgement), or not (in the case of imagining); and both may provide us with reasons for belief, or not (with the same division of cases). The main attitudinal difference between thoughts and experiences is that only thoughts can be responsive to epistemic reasons - and, for that matter, only thoughts with a judgemental attitude, which include occurrent (or conscious) beliefs and semantic memories - but not experiences. ${ }^{6}$

But that thoughts and experiences may share the same attitudinal aspects indicates that the related part of cognitive phenomenology cannot be discussed independently of experiential phenomenology. More specifically, any arguments that support skepticisim solely with respect to the existence of cognitive phenomenology, but not with respect to experiential phenomenology, are not applicable to attitudinal aspects. This is the second reason for studying attitudinal aspects - at least for defenders of cognitive phenomenology - since it renders many objections to cognitive phenomenology ineffective. ${ }^{7}$

The same strategy cannot be applied to presentational aspects because thoughts and experiences involve distinct forms of presentation. For example, while solely experiences are perspectival and connected to a sense modality, only thoughts allow for negation and similar logical operations (e.g. Crane 2009). There is an ongoing debate about how best to describe this difference in presentation. ${ }^{8}$ But its mere existence is already enough to ensure that it is possible to question the phenomenological salience of presentational aspects in the case of thoughts, while accepting their phenomenological salience in the case of experiences.

In this article, I aim to defend the phenomenological salience of two particular attitudinal aspects of thoughts (as well as of experiences): their rational role and their determination. My main focus is thereby on the presentation and motivation of Phenomenal Rationalism - or, as I called it in Dorsch 2011, Experiential Rationalism - concerning thoughts. What this view claims is that their rational role is phenomenologically salient:

Phenomenal Rationalism about Thoughts The rational role of thoughts is constitutive of, or otherwise reflected in, their phenomenal character.

The phenomenal character of mental episodes - such as conscious thoughts or experiences - is identical with what they are like from the inside for the subject who has them. ${ }^{9}$ It thus comprises all those aspects or features of the mental episodes that are accessible to the subject through introspection. ${ }^{10}$ If two mental episodes differ in which properties they introspectively seem to have, then they differ in phenomenal character.

The rational role of mental episodes, on the other hand, consists in their capacity to respond to reasons provided by other mental episodes or states, as well as in their capacity to provide - or at least contribute to the provision of - reasons for other mental episodes or states (or, indeed, actions). ${ }^{11}$ The rational role of mental episodes can be rather complex. For example, the rational role of (not self-justifying) judgemental thoughts - or judgements, for short - exhibits at least three elements, each of them linking judgemental thoughts to epistemic reasons (or evidence) in 
a distinct way: ${ }^{12}$

(SENS) Judgemental thoughts are sensitive to, or responsive to, certain epistemic reasons.

(BASE) Judgemental thoughts are based on, or responses to, certain epistemic reasons.

(PROV) Judgemental thoughts provide us with certain epistemic reasons, whether on their own or in conjunction with other mental episodes or states.

Phenomenal Rationalism about judgemental thoughts is thus the claim that their phenomenal character reflects them as possessing a rational role that can be characterised by means of (SENS), (BASE) and (PROV); while the rational role of other thoughts or mental episodes needs to be spelled out in different ways. One specific motivation behind the endorsement of Phenomenal Rationalism - which I do not aim to defend here any further - is that, if the rational role of mental episodes were not phenomenologically salient, then the reasons concerned might not count as our reasons. They become reasons for us (i.e. reasons that speak with normative authority to our rational faculties) only in so far as their presence and rational impact is accessible to us from the inside, that is, from our first-person perspective. ${ }^{13}$ The considerations in this article are thus centred around the idea of consciousness being shot through and through with rationality.

Of course, not all judgemental thoughts actually show each, or even any, of the three elements (SENS), (BASE) and (PROV). If one of our judgemental thoughts is causally induced by an intense emotional feeling (e.g. when an eruption of jealousy lets us falsely judge that our rival, who is otherwise unknown to us, is a mean person), it is not based on reasons and perhaps also not responsive to them (e.g. open to counterevidence). And because of its merely causal origin, our judgemental thought is also deprived of any justificatory power with respect to further judgements and beliefs. But, if everything works normally, judgemental thoughts are both responses to - and, hence, also responsive to - and providers of epistemic reasons. Our judgement that the streets are wet, for instance, may be grounded in our perception of the wet streets, may be open to new evidence (e.g. if we come to learn that the streets are just painted with a special kind of pigment that makes them look wet) and provides support for the further judgement that it has rained, as well as many other judgements.

What examples like these also illustrate is that rational role is closely linked to determination. Which content and attitude our mental episodes involve is determined by factors external to them, as well as at which moment in time they occur and how long they stay in existence. In the first example, the determinant of our judgemental thought is an emotion, and its influence on our judgement is merely causal. As a result, our judgemental thought lacks justificatory power and perhaps also any sensitivity to counterevidence. By contrast, our second judgemental thought is rationally determined by perceptual evidence and, as such, responsive to epistemic reasons and able to ground further beliefs. This connection between rational role and determination is crucial for my argument in support of Phenomenal Rationalism. More specifically, I intend to argue that 
the rational role of thoughts (and experiences) is phenomenologically salient in virtue of the phenomenological salience of how they are normally determined. That is, judgemental thoughts are phenomenally marked as being responsive to, and providing us with, epistemic reasons because they are phenomenally marked as being determined by such reasons (even if they happen to be merely causally determined).

In addition to this introduction, the article comprises three more sections. In the first, I present a long argument in favour of the view that judgemental thoughts are phenomenally marked as reasonable (even if they are in fact unreasonable), and that this involves the phenomenological salience of (SENS) and (BASE). The second section then defends the view that the phenomenal character of judgemental thoughts also reflects them as conforming to (PROV). My defense is thereby introduced by an extended discussion of the parallel case of perceptual experiences, which also seem from the inside to be providing us with epistemic reasons. In the third and final section, I briefly discuss how specific the introspectively accessible rational role of judgemental thoughts is (e.g. whether two judgements may differ phenomenally with respect to their rational role), and how this might bear on the issue of whether the content of thoughts is phenomenologically salient in addition to their attitude. In addition, I suggest how to extend my case for Phenomenal Rationalism to imaginative thoughts and experiences (i.e. by understanding them as responses to special practical reasons), as well as to episodic memories, pictorial experiences and other mental episodes.

\section{The responsiveness to reasons}

In this section, I aim to present a complex argument for the claim that judgemental thoughts are phenomenally marked as having a rational role that includes (SENS) and (BASE). The parallel claim with respect to (PROV) is then to be defended in the following section. But before I engage with the argument in support of the claim that (SENS) and (BASE) are phenomenologically salient, it is worthwhile to point out that self-justifying judgements (e.g. 'I am here now' or 'I am thinking that it rains') might be an exception to this specific claim although not to Phenomenal Rationalism in general.

Examples of self-justifying judgements are judgements that are conceptually true (e.g. 'I am here now') or self-verifying (e.g. 'I am thinking that it rains'), but perhaps also (self-)evident or certain judgements (e.g. 'I experience redness' or 'I exist'). The reasonableness of such judgements is the result of one of their other salient features which is independent of their origin or mental context - for instance, their necessity, infallibility or obviousness. Because of their possession of such a special feature, they end up justifying themselves, without the need for, or involvement of, any external support. But this means also that they enter into a reflexive rational relation, the two relata of which are one and the same judgemental thought (i.e. the selfjustifying judgements themselves). Whether (SENS) and (BASE) are true of self-justifying judgements thus depends on whether, by entering into these self-reflexive rational relations, these judgements count as reasons for themselves. I do not see why not. ${ }^{14}$ But even if it should turn out that (SENS) and (BASE) do not apply to self-justifying judgements, the following argument for the phenomenological salience of the rational role and, in particular, the reasonableness of judgements is still valid for all kinds of judgemental thought, independently of whether their reasonableness is due to their self-justifying power or to epistemic reasons external to them. 
The argument that I have in mind - an earlier version of which I already presented in Dorsch (2009a) - argues that the phenomenal character of judgemental thoughts reflects their reasonableness and, as a consequence, also the aspects (SENS) and (BASE) of their rational role (or their self-justifying power, if applicable). In other words, it is my contention that it makes a phenomenal difference to judgemental thoughts (e.g. in contrast to imaginative thoughts) that they have the rational role to be based on, and to be responsive to, epistemic reasons. Horgan and Timmons (2007) agree that (BASE) is phenomenologically salient in the case of judgemental thoughts (or occurrent beliefs); and Kriegel (2015, ch. 1) puts forward the same claim with respect to (BASE) and (PROV). But they do not provide any argument for this view, apart from some anecdotal introspective reflections. My aim in this section is to remedy this situation.

The argument starts with the assumption that we normally take our judgements to be reasonable (or, if one prefers, formed in a reasonable manner). Indeed, we typically assume them to be occurrent instances of knowledge, which includes that we take them not only to be reasonable, but also to be non-accidentally true. If this were not the case, we would not have any tendency to rely on our judgements in belief and agency, nor any tendency to revise them once we come to suspect that they might be unreasonable or false (e.g. when encountering counterevidence). But we do have these and similar tendencies, at least if we are fairly rational which means that we do take our judgements to be reasonable (as well as non-accidentally true and instances of knowledge).

That we normally take our judgemental thoughts to be reasonable becomes manifest in the fact that we form a respective higher-order judgement when considering the issue. That is, when we ask ourselves (or are asked by someone else) whether one of our judgements is reasonable, we typically end up judging that it is. This raises the issue of how to account for the occurrence of this higher-order judgement and, in particular, of the ascription of the property of being reasonable. ${ }^{15}$ There are basically three options of how we can get from questioning whether a given lower-order judgement is reasonable to forming the higher-order judgement that this lower-order judgement is reasonable:

The Inference Model The higher-order judgement is the conclusion of a conscious inference that we engage with in response to asking the question.

The Prompting Model Considering the question prompts the higher-order judgement in a phenomenologically spontaneous and immediate manner.

The Awareness Model The higher-order judgement is the result of the conscious abstraction from, and conceptualisation of, a non-conceptual awareness of the reasonableness of the lower-order judgemental thought - an awareness that we pay special attention to in response to asking the question.

The Inference Model maintains that we judge that our lower-level judgemental thought is reasonable in conscious response to introspectively recognising that it is a judgement, and to believing that judgements generally are reasonable (at least if they are based on standard kind of evidence, and unless we are aware of defeating circumstances). But this account 
overintellectualises the formation of the higher-order judgement. Usually, we need not engage in any form of conscious inference in order to judge that one of our judgemental thoughts is reasonable. We arrive at our higher-order insight in a phenomenologically more immediate way. Furthermore, small children, too, rely on their judgements when forming beliefs and intentions and thus should count as taking their judgements to be reasonable, even though many of them lack the conceptual apparatus required for engaging in the kind of inference posited by the Inference Model.

A proponent of the Inference Model might reply that the inferences in question need not be conscious. However, this move does not help with the case of small children, given that they would still lack the required conceptual capacities. In addition, the proposal faces a dilemma with respect to the objection concerning phenomenological immediacy. On the one hand, the non-conscious inferences might be such that we are still able to render them conscious. But this would not cover all possible cases, given that we certainly can form higher-order judgements about the reasonableness of our judgemental thoughts even when we are unable to produce any conscious inferences that conclude in those higher-order judgements. On the other hand, the nonconscious inferences might instead be such that they are incapable of becoming manifest in consciousness. But, then, we should treat them as purely causal rather than as rational inferences, given that responding to reasons (whether they are inferential or not) is a deliberative or personal, and not a subpersonal, phenomenon (see endnote 13 for references). Accordingly, the Inference Model would simply reduce to the Prompting Model.

The Prompting Model faces its own difficulties, however. It suggests that our higher-order judgement occurs in direct and automatic response to wondering whether our lower-order judgemental thought is reasonable. In some cases, the higher-order judgement might simply manifest an already existing higher-order belief about the reasonableness of the lower-order judgemental thought. But not only are there many cases in which there is no such prior higherorder belief. We also need an explanation of how we have acquired this higher-order belief presumably by means of some initial higher-order judgement that is no manifestation of any prior belief. Hence, the spontaneous and immediate formation of higher-order judgements postulated by the Prompting Model cannot be accounted for simply in terms of belief manifestation.

Similarly, it cannot be understood as the result of some constitutive link between the lowerorder judgemental thought and the higher-level judgement. Some philosophers have argued that, if we are rational and possess the required concepts, having the (occurrent) belief that $p$ is sufficient for inclining us to judge that we believe that $p$. Indeed, they maintain that this is part of what it means to be rational and have beliefs (Shoemaker 1994; Burge 1998, 1996), or to be rational and possess the concept of 'believing' (Peacocke 1996, 1999). Irrespective of whether their argument is successful with respect to higher-order ascriptions of the property of being a belief, it cannot be extended to higher-order ascriptions of the property of being reasonable. Having a judgemental thought - plus being rational and possessing the relevant concepts - is simply not sufficient for having the higher-order belief that this judgemental thought is reasonable. In particular, it is not a condition on our possession of the concept 'reasonable' (or 'reasonable judgement') that rational agents are disposed to judge that one of their judgemental thoughts is reasonable whenever that judgemental thought is indeed reasonable. In other words, while there might indeed be a constitutive link between believing that $p$ and being inclined to 
judge that one is believing that $p$, there is no such link between judging that $p$ and being disposed to judge that (this instance of) judging that $p$ is reasonable. Alternatively, proponents of the Prompting Model may assume that a merely causal process is the source of the higher-order judgements. According to this proposal, having a judgemental thought and wondering whether it is reasonable normally causes us to judge that it is reasonable. The problem for this view is, however, to explain why this kind of causation occurs. That judgemental thoughts are more likely to be reasonable than not can at best account for the content of the resulting higher-order judgement (as well as for the content of the triggering question), but not for its occurrence. There is nothing to the property of being formed in a reasonable manner that could explain why its instantiation by a judgemental thought inclines us to form the respective higher-order judgement. So, the account should generalise from the case at issue and assume that introspection is a causal process across the board, independently of whether the ascribed property is reasonableness or another property. Moreover, in order to ensure that introspection can still lead to knowledge, the causal process said to be at its heart is presumably best taken to be reliable (O'Brien 2003) ${ }^{16}$

But there are good reasons to resist such a causal-reliabilist model of introspection. Since many of these reasons are well known, I merely list two of them here. First, the view faces the general problems of reliabilist accounts of knowledge, such as the generality problem or the new evil-demon problem (Goldman and Beddor 2015). Indeed, in the case of introspection, these problems might be even more pressing since we have no clear understanding of the causal processes involved in the formation of higher-order judgements and thus cannot specify any normal conditions under which the causation of such judgements ensures them to be true. ${ }^{17}$ Second, assuming merely a causal link between the lower- and higher-order states does not connect them intimately enough in order to account for some central features of their relationship. One such feature is that the higher-order judgements have an immediate rational impact on the lower-order thoughts. For instance, assuming that we are rational, our conclusion that one of our judgemental thoughts (or beliefs) is unreasonable will always move us to change the latter accordingly. But the mere causation of the higher-order state by the lower-order one could not ensure the inevitability of this rational impact, not only because the causal influence operates in the wrong direction, but also because causal connections can break down even under conditions of rationality. Indeed, while perception and other causal processes allow for brute error (i.e. error that is not due to the irrationality or malfunctioning of the subject), introspection does not (Shoemaker 1994; Burge 1996, 2003; Siewert 1998). This feature is closely linked to the fact that we cannot specify normal conditions for the causal processes said to be central to introspection, given that brute error can occur only under non-normal conditions.

Partly because of difficulties like these, Peacocke (1998) assumes that the link between the lower- and the higher-order states is not merely causal, but also rational in nature (see also Martin 2000a). However, he accounts for this rational connection in terms of the mental concepts involved (e.g. 'judging' or 'believing'): the lower-order state is a reason for forming the higherorder state because it is part of our possession of the relevant concepts that we normally apply exactly that concept to the lower-order state that correctly picks out its kind (e.g. judgemental thought or belief). Hence, despite not assuming the link between the lower- and higher-order states to be constitutive, Peacocke believes that, if we are rational and possess the required concepts, having a lower-order state of a certain kind (e.g. a belief) is sufficient for being inclined to form the higher-order judgement that the lower-order state is of that kind. As a result, 
he face the same problem as those who take the link to be constitutive, namely to motivate the extension of their view to higher-order judgements about the reasonableness of the lower-order states. $^{18}$

Because both the Inference Model and the Prompting Model fail to provide a satisfactory account of why we normally judge our judgemental thoughts to be reasonable, we should look for a better alternative. The only remaining plausible option is to endorse the Awareness Model, according to which our higher-order judgements are conceptual endorsements of a corresponding non-conceptual awareness of reasonableness. In other words, we judge our judgemental thoughts to be reasonable because we are non-conceptually aware of them as reasonable (and have no reason not to take this awareness at face value).

The awareness in question is not perceptual or even perception-like, for the same reasons that introspection is not a matter of inner observation (Shoemaker 1994; Martin 1997; Dorsch 2013). Rather, it is a kind of phenomenal awareness. ${ }^{19}$ It is part of what judgemental thoughts are like for us from the inside that they seem to us to be reasonable. And this phenomenological salience of their reasonableness is, of course, partly the result of the fact that judgemental thoughts are normally reasonable. ${ }^{20}$ In this respect, judgemental thoughts differ introspectively from imaginative thoughts. We do not take imaginative thoughts to be based on sufficient evidence (nor to be true or to constitute knowledge) precisely because their phenomenal character does not involve an aspect that marks them as reasonable.

That the reasonableness of standard judgemental thoughts is reflected in their phenomenal character entails that both (SENS) and (BASE) are phenomenologically salient. That judgemental thoughts are reasonable just means - at least if they are not self-justifying - that they are actually based on sufficient epistemic reasons (whichever they are). Hence, taking them to be reasonable involves taking them to be actual responses to some epistemic reasons, which again entails taking them to be generally responsive to (a certain kind of) epistemic reasons. So, the kind of awareness that grounds our higher-order judgements about reasonableness needs to be rich enough to be able to permit and support higher-order judgements about actual and potential responsiveness to epistemic reasons, too. But this implies that it is an awareness of responsiveness to epistemic reasons. In other words, that judgemental thoughts are normally based on, and sensitive to, epistemic reasons is part of their phenomenal character, that is, of what they are like from the inside. ${ }^{21}$ Depending on whether (SENS) and (BASE) apply to selfjustifying judgements, they either involve exactly the same kind of awareness of reasonableness as standard judgemental thoughts, or this awareness consists just in the phenomenal awareness of their self-justifying power.

It is important to note that the phenomenal awareness of responsiveness to epistemic reasons does not by itself put us into a position of being able to identify the reasons concerned (unless, perhaps, the judgemental thoughts justify themselves). ${ }^{22}$ Indeed, we are often unable to remember on the basis of which reasons we have formed our beliefs; and this ignorance extends to the judgemental thoughts that manifest those beliefs in consciousness. But even if we still know in response to which reasons we have formed a given judgemental thought (e.g. we may still enjoy the perceptual experience on which it is based), our recognition of the identity of these reasons has to go beyond our phenomenal awareness of our judgemental thought (e.g. it has to include our phenomenal awareness of our perceptual experience as well).

Similarly, that the phenomenal character of judgemental thoughts marks them as reasonable 
or reflects them as having a certain rational role neither involves, nor requires concepts especially not normative concepts like 'reasonable', 'reasons' or 'rational role'. In short, phenomenal awareness is non-conceptual, despite the fact that it certainly allows for a process of abstraction and conceptualisation that leads to corresponding thoughts - for instance, when we employ the concept 'reasonable' in response to our phenomenal awareness of reasonableness of a given judgemental thought and come to judge that thought to be reasonable. ${ }^{23}$ All that is implied by saying that we are phenomenally aware of some mental episode as having a certain property is that having this property makes a phenomenal difference for the subject concerned - that is, it influences what the episode is like for the subject from the inside and thus distinguishes it phenomenally from episodes that lack the property in question (Dorsch 2013, 2017a).

\section{The provision of reasons}

With respect to the defense of Phenomenal Rationalism concerning judgemental thoughts, this leaves the task of supporting the claim that their phenomenal character reflects aspect (PROV) of their rational role. To see why judgemental thoughts are phenomenally marked as contributing to the provision of epistemic reasons (and not only as being responsive to them), it is helpful to compare judgemental thoughts with perceptual experiences. In both cases, we get clearer about the phenomenal character of the experiences or thoughts concerned, once we reflect on the introspective indistinguishability of non-veridical instances from veridical ones, as well as on their phenomenal contrast with imaginative experiences or thoughts. But since the introspective indistinguishability of hallucinations (and illusions) from veridical perceptions is better understood and easier to characterise than its cognitive counterpart, it is helpful to develop the line of argument first with respect to perceptual experiences, before adopting more or less the same argumentative strategy to judgemental thoughts.

Let me begin with the epistemology of perception. Conscious veridical perceptual experiences make us aware of perceivable features of external (i.e. experience-independent) objects in our actual surroundings. More specifically, how they present their objects as being is fully determined by how those objects really are. For instance, a veridical perception makes us aware of a book as blue and rectangular just in case, and because, the book concerned is indeed blue and rectangular. ${ }^{24}$ This relation of determination is epistemologically significant in so far as we could not be in any better epistemic position with respect to the perceivable properties of external objects. Having a conscious experience of which it is true that how it presents things as being is contingent solely on how they really are provides us with the best - that is, the most conclusive or truth-conducive - access to the external world possible. ${ }^{25}$ Hence, if perceptual experiences do not provide us with reasons for beliefs about the perceivable aspects of the external world, nothing will do (which, of course, is why perception has always been at the centre of skepticism concerning the external world).

Now, I argue elsewhere (Dorsch 2017a) that the determination of veridical perceptual experiences by their objects is phenomenologically salient and, in fact, introspectively seems to pertain to all perceptual experience, not only veridical ones. Perceptual experiences are characterised by the fact that they are introspectively indistinguishable from veridical perceptions. ${ }^{26}$ This is trivially true of veridical perceptions, but also applies to (perfect) illusions and hallucinations. For even when we have a non-veridical perceptual experience, we still take it to be veridical - unless, of course, we have evidence to the contrary from the outside (e.g. 
evidence delivered by testimony or further perceptual observation). In other words, from the inside, the non-veridicality of our illusions and hallucinations is not apparent to us. If it were, we would not - as we actually do - rely on our perceptual experiences by default when forming beliefs and perfoming actions, even if they happen to be non-veridical. Only when our experiences are contradicted by further observations or by what others say do we start to question their veridicality and possibly cease to take them at face value. What this asymmetric introspective indistinguishability of non-veridical perceptual experiences from veridical ones reveals is that the phenomenal character of perceptual experiences marks them as veridical even if they are not. ${ }^{27}$

It is here that the previous considerations about the epistemologically significant determination of veridical perceptual experiences by their external objects become important. For veridical and non-veridical perceptual experiences differ precisely in whether their presentation of our surroundings is fully determined by the actual nature of our surroundings. When we misperceive a white book to be blue or even hallucinate a blue book, which colour we experience to be instantiated before our eyes is not a function of which colour is in fact instantiated before our eyes. Hence, that the phenomenal character of both veridical and nonveridical perceptual experiences reflects them as being veridical means, at least in part, that it reflects them as presenting how things are contingent on how they actually are. In other words, it is part of what perceptual experiences are like for us from the inside that their presentation of perceivable properties seems to be fully determined by perceivable properties instantiated in our environment.

There are two central aspects to the phenomenological salience of the (apparent) determination by external objects: that the objects experienced seem to be external (i.e. experience-independent); and that they seem to be determinants of how the experience in question presents things as being. It has often been observed or mentioned that perceptual experiences are transparent in the sense that, whenever we are attending to them from the inside, we end up noticing the objects and features that they make us aware of, and which seem to be part of our surroundings. ${ }^{28}$ But we do not merely notice the (apparent) presence of those objects and their features. We also notice their (apparent) externality or experience-independence (McDowell 1998; Siegel 2006; Dorsch 2017a). This means that, from the inside, the objects of our perceptual experiences seem to exist and to instantiate their perceivable properties independently of being experienced by us. As Tye, for example, notes: 'In turning one's mind inward to attend to [an] experience, one seems to end up concentrating on what is outside again, on external features or properties' (Tye 1995, 30). ${ }^{29}$

More specifically, we have the impression that the objects of our perceptual experiences did already enjoy their existence and their perceivable properties before the occurrence of our experiences, and will continue to do so after we stop experiencing them. And this impression is accompanied by a sense of their being public objects and features that are accessible through perception to others, too. In this respect, perceptual experiences differ phenomenologically from experiences of after-images. When we are experiencing a yellow after-image, say, the experienced yellow spot does not seem to be part of our actual environment (e.g., it 'moves around' in accordance with our eye movements, and completely disconnected from the objects in our surroundings); and it also does not appear to exist independently of our experience of it, nor as a public entity open to further observation by others. 
What matters, when we turn to the aspect of determination, is not our impression of what will happen to the objects experienced if our perceptual experiences change, but rather our impression of what will happen to our perceptual experiences if their objects change. When we attend from the inside to our perceptual experiences, their transparency ensures that we come to notice the various perceivable properties that the objects of our experiences seem to instantiate. But, crucially, we do not distinguish from the inside between how the experiences present their objects as being and how those objects really are. Of course, we are aware that our perceptual experiences might be non-veridical. But, as already mentioned, unless we have reason to doubt their veridicality, we take them to be veridical. As a result, we expect our perceptual experiences to change if the perceivable properties of their objects should change. For instance, when we are perceiving a white and rectangular canvas, we anticipate that, if the canvas is painted green or cut to a square shape, our experience will stop presenting it as blue and rectangular and start presenting it as green and square. ${ }^{30}$ The preceding considerations reveal that both the externality and the determining role of the objects of our perceptual experiences are phenomenologically salient: it is part of what our perceptual experiences are like that their objects appear to be external and to determine how the experiences present them as being. But, as argued at the beginning of this section, being determined by aspects of the external world just amounts to providing us with the best possible access to that world. Hence, our introspective impression that our perceptual experiences are determined by their objects renders that feature of the experiences phenomenologically salient, in virtue of which the experiences provide us with epistemic reasons. It is in this sense that their role as reason-providers (PROV) is accessible to us from the inside. This rational aspect of their phenomenal character distinguishes perceptual experiences from their imaginative counterparts. How we visualise objects as being, say, is not determined by the visible properties of the objects in our surroundings. ${ }^{31}$ Correspondingly, it is not part of what our imaginative experiences are like to us from the inside that they seem to be determined by external objects. Instead, they typically are - and appear to be - determined by the relevant practical reasons or goals that we are aware of by way of our conscious intentions or desires to imagine certain things. ${ }^{32}$ We visualise a very tall person, for instance, because this is what a certain novel or thought experiment, with which we intend to engage, requires us to do. In other words, we are usually aware of our imaginative experiences as being part of, or the result of, actions of imagining. The phenomenologically salient difference in how perceptual and imaginative experiences are determined thus concerns also their link to mental agency. For while imaginative experiences normally seem to us to be determined in an active manner, their perceptual counterparts appear to be determined in a passive manner - at least, with respect to how they present things as being.

The main point of introducing this complex argument to the effect that the phenomenal character of perceptual experiences reflects their capacity (PROV) to provide us with reasons is that we can develop a very similar line of reasoning with respect to judgemental thoughts. Let me again begin with some epistemological considerations. Judgemental thoughts usually give rise to beliefs if certain conditions are met (e.g. if their subject matter is important enough and they remain undefeated). Moreover, if the judgemental thoughts concerned are reasonable and non-accidentally true, they typically lead to beliefs that constitute knowledge (or, if one assumes that knowledge cannot be further analysed, are implied by a corresponding state of knowledge). For want of a better term, we may call judgemental thoughts that put us into a position to acquire 
knowledge knowledgeable. Typically, judgemental thoughts cannot ground knowledge on their own, but require the help of additional judgements or beliefs. The reason for this is that judgemental thoughts provide primarily inferential reasons, and that most inferences involve more than one premiss. ${ }^{33}$ For instance, once we come to knowledgeably judge that the streets are wet, we can infer that it has raised only conditional on the ancillary belief that rain is the best explanation for the wetness of the street.

Now, knowledgeable judgemental thoughts are reasonable because they are formed on the basis of sufficiently good or strong epistemic reasons - reasons which may be provided by perception, inference or any of the other sources of knowledge. The epistemic reasons concerned thereby play a triple role. ${ }^{34}$ First, they determine that the thoughts concerned involve a judgemental attitude towards their propositional contents (i.e. the attitude of taking the respective propositions to be true for the sake of truth), rather than some other attitude. That we judge (rather than imagine or desire, say) something to be the case is due to the fact that our relevant reasons are reasons for belief, that is, epistemic reasons. Second, they determine which propositions are judged to be true as part of the judgements. That is, the epistemic reasons determine how the knowledgeable judgemental thoughts present things as being. For instance, that we judge - and come to know - that a book is red (rather than yellow) is due to the fact that our judgement is suitably based on a veridical perception of the book's redness; or, alternatively, on a sound inference starting from the known premisses that the book's surface reflects light of a wavelength of about 650 nanometres, and that surfaces with this reflectance property are red. Second, the epistemic reasons ensure that the judgemental thoughts turn out to be nonaccidentally true. Of course, not all reasonable judgements are true, let alone non-accidentally. But if they are non-accidentally true and knowledgeable, their truth is due to the determination of their propositional content by the epistemic reasons in questions. Our judgement that the book is red is non-accidentally true because its content is determined solely by how the underlying veridical perception presents the book as being; or solely by how the true premisses of the underlying sound inference entail the book as being. ${ }^{35}$

Parallel to the argument concerning perceptual experiences, the main claim is now that the rational determination of knowledgeable judgemental thoughts is phenomenologically salient and, furthermore, that this aspect of phenomenal character is also present in the case of nonknowledgeable (i.e. unreasonable or at best accidentally true) judgemental thoughts. It is distinctive of judgemental thoughts (or occurrent beliefs) that they are introspectively indistinguishable from knowledgeable judgemental thoughts (or occurrent propositional knowledge). As already noted in section 2, we take all our judgemental thoughts to be knowledgeable - which includes taking them to be reasonable and non-accidentally true - unless we have evidence to the contrary (in which case we tend to revise or give up our judgements if we are sufficiently rational). Moreover, as also argued earlier, our awareness of the reasonableness of our judgements forms part of what they are like for us from the inside. Exactly the same argument applies to our awareness of them as non-accidentally true and, hence, as knowledgeable. We take our judgemental thoughts to be non-accidentally true and knowledgeable neither as the result of some inference about them, nor due to some causalreliable or constitutive link between having a judgemental thought and being inclined to judge it to be non-accidentally true and knowledgeable. Instead, all judgemental thoughts are introspectively indistinguishable from knowledgeable judgemental thoughts because their 
phenomenal character marks them as knowledgeable - even if they are not. ${ }^{36}$

If we combine this phenomenological observation with the epistemological one that the knowledgeability of judgemental thoughts is due to their determination by sufficient epistemic reasons, we can get a clearer idea of what it means for judgemental thoughts to seem to be knowledgeable from the inside. Whether a judgemental thought counts as knowledgeable depends essentially on whether it is determined by sufficient epistemic reasons. Hence, that judgemental thoughts are phenomenally marked as knowledgeable means minimally that they are phenomenally marked as being determined by sufficient epistemic reasons. More specifically, it is part of what judgemental thoughts are like for us from the inside that both their attitude and their content seem to be determined by sufficient epistemic reasons - again with the proviso that this does not require that we are also aware of the specific identity of the reasons that the judgemental thoughts are based on (if any).

It is here that the analogy with perceptual experiences breaks down to some extent. For our awareness of the reasons that (seem to) determine our judgemental thoughts differs greatly from our awareness of the objects that (seem to) determine our perceptual experiences. While the impression of the rational determination of judgemental thoughts is as such devoid of any specificity with respect to the nature of the reasons concerned, the impression of the external determination of perceptual experiences is always accompanied by a presentation of some of the perceivable features of the objects in question (indeed, it is determined how those objects are presented as being). As a result, judgemental thoughts - unlike perceptual experiences - are not transparent to those entities that determine them. If at all, judgemental thoughts are transparent to the propositions that they are attitudes towards. ${ }^{37}$

But this phenonmenological difference does not prevent the property of being determined by (otherwise unidentified) sufficient epistemic reasons to be as phenomenologically salient as the property of being determined by external objects (with certain perceivable properties). For, in both case, we expect our experiences or thoughts to change in relevant ways in response to changes in their determinants; and we have this expectation primarily because, from the inside, we do not distinguish between how those determinants are and how they seem to be according to our experiences or thoughts. In the case of judgemental thoughts, this means that we do not differentiate between having (had) sufficient epistemic reasons for forming the judgement and having a reasonable judgement, that is, a judgement based on sufficient epistemic reasons. In other words, by being phenomenally marked as reasonable (or, indeed, knowledgeable), judgemental thoughts 'present' the relevant reasons as sufficient for grounding knowledgeable judgements; and we do not distinguish between how the reasons are 'presented' and how they really are. We certainly know that we are not infallible with respect to our stance concerning the sufficiency (and existence) of the epistemic reasons that our judgemental thoughts seem to be based on. But, by default, we take our judgemental thoughts to be reasonable, that is, grounded in and determined by sufficient epistemic reasons.

Indeed, if this were not the case, it could not be explained why we anticipate that our judgemental thoughts will change if our reasons change - for instance, if they cease to be sufficient for judgement, or if they start to support a different judgement than before. This expectation is furthermore heightened by our recognition that epistemic reasons usually obtain independently of the judgements that they support. For the fact that we take our judgemental thoughts to be essentially connected to epistemic reasons, but also know them not to be 
determined by our judgements (or some third factor which simultaneously influences our judgements), already entails that we take our judgements to be determined by the relevant reasons (whichever they are). That is, given the judgement-independence of epistemic reasons, the assumed relation of dependence has to run in the opposite direction. But our phenomenal awareness of the (apparent) sufficient rational determination of our judgemental thoughts renders that feature phenomenologically salient that is responsible for the status of our judgemental thoughts as (seeming) providers of epistemic reasons. Judgemental thoughts provide us with reasons for further beliefs precisely because they are rationally determined by sufficient epistemic reasons. And this connection, together with our phenomenal awareness of rational determination, provides us with access from the inside to the aspect (PROV) of the rational role of judgemental thoughts.

Like in the case of perceptual experiences, the rational dimension of their nature and phenomenal character differentiates judgemental thoughts from their imaginative counterparts. The attitude and content of imaginative thoughts are not determined by epistemic reasons, but by practical reasons (or perhaps also by non-rational factors - see endnote 32). We imagine that the Earth is flat because we want to engage in a thought experiment of how life might be on a flat disk, say; or we imagine that Sherlock Holmes lives in Baker Street 221b because we aim to properly engage with Conan Doyle's stories, and this requires imagining what is fictional in those stories (Walton 1990). That imaginative thoughts are not formed in response to epistemic reasons implies that they cannot lead to knowledge and contribute to the provision of reasons for belief, as revealed by the fact that imagined premisses can solely provide support for imagined conclusions (Dorsch 2016a). Moreover, their lack of the capacity to respond to and provide us with epistemic reasons is phenomenologically salient: it is part of what imaginative thoughts are like for us that they are outside of the net of epistemic rationality.

\section{Extending the scope of Phenomenal Rationalism}

The preceding considerations have made the case for the claim that the phenomenal character of judgemental thoughts (or occurrent beliefs) reflects the three aspects of their rational role described by (SENS), (BASE) and (PROV). In addition, I have argued that perceptual experiences are phenomenally marked as sharing the last aspect (PROV) with judgemental thoughts. Before concluding this article, I would like to briefly consider two further issues: how specific the salient attitude and, especially, rational role of judgemental thoughts is and what this means for the salience of their content; and how Phenomenal Rationalism may be applied to many, if not all, other kinds of mental episode.

The first issue concerns the question of whether there are phenomenologically salient aspects of the rational role of judgemental thoughts that - unlike (SENS), (BASE) and (PROV) - may differ between distinct judgemental thoughts. The three elements of rational role discussed so far specify that judgemental thoughts provide us with, and are responsive to, certain epistemic reasons - that is, epistemic reasons that are variable (i.e. may differ between distinct judgemental thoughts) and particular (i.e. accessed by us in virtue of particular mental episodes or states, such as individual beliefs or perceptual experiences). But (SENS), (BASE) and (PROV) remain silent on the different identities, or more determinate natures, of the reasons that figure in the distinct rational roles of specific judgemental thoughts. For example, the judgement that the sky is 
cloudless - but not the judgement that today is Sunday - is sensitive to the perceptual or inferential recognition that it has started to rain. Similarly, the two judgements make it reasonable to infer that there will be many people at the zoo, say, only in conjunction with very different ancillary beliefs about when people normally like to visit the zoo (namely, respectively, on sunny days or on Sundays).

Such differences in rational role are intimately connected to the fact that both the reasonableness and the justificatory power of judgemental thoughts are relative to their propositional contents. It is never just reasonable to judge, but to judge that $p$ (where ' $p$ ' denotes the specific propositional content of the judgement concerned); and knowledgeable judgemental thoughts - together with other mental episodes or states - never just provide us with a reason to infer, but to infer that $q$ (where ' $q$ ' picks out the specific inferentially supported conclusion). The question is now whether judgemental thoughts, in being phenomenally marked as reasonable and as contributing to inferential reasons, are also phenomenally marked as responsive to reasons for judging that $p$ or as providing rational support for judging that $q$. If so, it seems possible to formulate an argument for the phenomenological salience of the varying propositional contents of judgemental thoughts on the basis of the phenomenological salience of their attitudes and, in particular, their distinct specific rational roles. ${ }^{38}$

In parallel to the argument presented in section 2, the crucial observation is that our judgemental thoughts incline us to judge not only 'our judgement is reasonable', but also 'our judgement that $p$ is reasonable' (or, alternatively, 'it is reasonable for us to judge that $p$ '). For example, when we entertain the judgemental thought that it rains, say, and ask ourselves whether this judgemental thought is reasonable, we normally end up forming the higher-order judgement that our judgement that it rains is reasonable - and not merely that this judgement is reasonable, irrespective of which propositional content it has. In short, taking our judgemental thought to be reasonable involves taking it to be reasonable for us to judge that it rains (and not, say, that the sun is shining).

Moreover, this higher-order judgement is not inferentially derived from the simpler higherorder judgement that our judgemental thought is reasonable and the additional belief that the judgemental thought concerned has the propositional content that it rains. We need not engage in inferences of this kind in order to conclude that, as part of judging that $p$, we take it to be reasonable for us to judge that $p$. Nor is the higher-order judgement simply the phenomenologically spontaneous result of some constitutive link or reliable causal process, for the reasons already rehearsed in section 2. This leaves, again, the Awareness Model as the best option, according to which we are inclined to take our judgemental thoughts reasonable relative to their particular propositional contents because we enjoy some non-conceptual - and, presumably, phenomenal - awareness of this relativised reasonableness.

As a consequence, we should extend Phenomenal Rationalism from the general rational role common to all judgemental thoughts to some of the more specific differences between the distinct rational roles of the individual judgemental thoughts. In other words, the what is phenomenologically salient is not just the determinable rational role shared by all judgemental thoughts, but also the various content-specific determinations of this role by particular judgements. For taking the judgement that $p$ to be reasonable means taking it to be based on and, hence, also sensitive to - sufficient reasons for judging that $p$. And this certainly implies the phenomenological salience of the propositional content $p$ of the judgemental thought itself. The 
salience of attitude is thus, in this way, intimately linked to the salience of content.

Moreover, once it is established that our judgement that $p$ introspectively seems to be wellsupported by reasons for judging that $p$, it is not difficult to show that the judgemental thought may also be phenomenally marked as contributing to the provision of a reason for judging that $q$ (rather than just some unspecified epistemic reason) - for instance, when the judgement that $p$ is considered in conjunction with the judgement that, if $p$, then $q$. Of course, the resulting impression of having a reason for judging that $p$ pertains to the phenomenal character of the mental complex that comprises both the judgement that $p$ and the judgement that, if $p$, then $q$. But this just suggests that there is a contextual or holistic dimension to the phenomenal character of judgemental thoughts: namely that which specific aspects of its reason-giving power happen to be phenomenologically salient may partly depend on which other mental episodes occur concurrently, notably in the context of conscious reasoning.

The second issue still to be addressed concerns the applicability of Phenomenal Rationalism to other kinds of mental episode. Let us consider imaginative experiences and thoughts first. That they introspectively seem to lack the same rational role as their cognitive counterparts does not mean that they possess no phenomenologically salient rational role at all. Given that imagining is typically a conscious mental action, it comes with the phenomenal awareness of agency which, as I have argued elsewhere (Dorsch 2009a), is best understood as the phenomenal awareness of their response - and responsiveness - to some practical reasons (e.g. those presented or embodied by intentions, desires, normative judgements, and the like). Moreover, acts of imagining differ from other instances of mental agency in at least three phenomenologically salient ways.

First, while episodes of imagining are themselves presentational, other mental actions are not and, at best, merely operate on presentational - and usually non-imaginative - experiences or thoughts (e.g. when we actively try to recall something, to calculate a sum in our head, or to change our mood by meditating). Given that many presentational differences give rise to phenomenal differences (e.g. with respect to how things are presented as being, or in which sensory modality), this should also be true of the basic presense or absence of presentationality.

Second, imagining differs from other forms of mental agency in that it is rationally responsive only to a certain subset of practical reasons, namely those reasons that speak in favour of actively and directly forming experiences of, or thoughts about, specific objects and features (Dorsch 2009a, 2012, ch. 13). Although probably not all differences in practical rationality are open to introspection, this particular difference is very likely to be phenomenologically salient because it concerns the fundamental distinction between what is under our active control and what is not. For while it is not up to us what we are perceiving, judging, remembering, feeling, and so on (but at best when we do so), we have active and direct control over how imaginative experiences and thoughts present things as being.

Third, imaginative (and other) mental actions differ phenomenally from conscious motivational episodes - such as occurrent intentions, desires or normative judgements - in that they introspectively seem to be active, but mediated reponses to practical reasons, while the motivational episodes appear to respond to practical reasons in a passive, but immediate way (Dorsch 2009a). In particular, while reasons directly compel us to form motivational episodes, their impact on actions is merely indirect in so far as it is mediated by the relevant motivational 
episodes. We come to intend to visualise something in response to recognising that we have reason to do so; and our resulting episodic act of imagining is determined by, and remains sensitive to a change in, our practical reasons in so far as it is motivated and guided by our relevant intention (or intention-in-action), which itself continues to be rationally influenced by our practical reasons, whether they are changing or not. Next are veridical episodic memories which differ from veridical perceptual experiences in that they are not determined by objects in our present surroudings, but rather by objects in our past surroundings (or, if one prefers, by our past veridical perceptions of those objects, which were again determined by those objects). This difference in object determination is clearly phenomenologically salient, giving rise to what have been often called impressions of the 'presence' or of the 'absence' from our environment of the objects concerned. ${ }^{39}$ More important, it also establishes a comparable difference in rational role, meaning that while perceptual experiences provide us with reasons for beliefs about the present, episodic memories provide us with reasons for beliefs about the past. And a similar line of reasoning as the one employed above in section 3 should suffice to motivate the conclusion that this rational difference contributes to what the respective experiences are like from the inside.

Another interesting kind of experience are pictorial experiences, not the least because they seem to combine elements of seeing with elements of visualising. ${ }^{40}$ Pictorial experiences make us visually aware of two things: the canvas and its visible properties; and the depicted object or scene and its visible properties. Our visual awareness of the canvas is certainly perceptual in nature and, as such, phenomenally marked as being determined by the visible properties of the canvas, and as providing us with reasons for perceptual beliefs about those properties (as well as for introspective beliefs about this perceptual aspect of the pictorial experience concerned). Interestingly, how our pictorial experience presents the depicted object as being is also determined by an external object in our current environment (which lets this aspect of pictorial experience resemble perception). But the determining object is of course not identical to the depicted object, given that the latter is normally not part of our external surroundings. Rather, the determinant of our visual awareness of the depicted is again the canvas. In particular, any changes in how we experience the depicted object as being can be traced to back changes in the visible properties of the canvas (e.g. in the shape, colour, location and texture of the marks of paint on it). And we may become aware of this fact once we reflect on our pictorial experiences from the inside. Pictorial experience is thus special in that it involves the phenomenologically salient determination of two presentations - one perceptual, the other not - by one and the same object.

Finally, even mental episodes that do not play any role in epistemic or practical reasoning and in same-order attitude formation - for instance, because they are non-presentational (e.g. moods) or causally originate in the brain in a completely passive and non-rational manner (e.g. afterimages) - may still possess at least one particular rational role, namely to provide rational support for their own self-ascription in the shape of introspective higher-order judgements. Assuming that it is right to say that all mental episodes are open to introspection, and that our knowledgeable introspective judgements about our mental episode are rationally grounded in those episodes (see, again, the discussion of Peacocke's view in section 2), it follows that all mental episodes turn out to provide epistemic reasons for introspective judgements. And if it is accepted that the reason-giving power of perceptual experiences and judgemental thoughts is phenomenologically salient, it seems difficult to deny the same with respect to other mental 
episodes.

What all these cases illustrate is that the phenomenological salience of rational role is inseparably linked to the phenomenological salience of determination, just as rational role is inseparably linked to determination. There are several basic differences in how distinct kinds of mental episodes are determined, notably with respect to whether the determinants are reasons or external objects and their features, and with respect to whether what is determined concerns primarily how the episodes present things as being or also which commitment or attitude they adopt towards what they present as being the case. For instance, reasons determine both content and attitude, while the impact of objects and their features seems to be largely limited to content (and possibly also time and duration of occurrence).

Moreover, these differences in determination affect which rational role the respective mental episodes possess and, hence, also what they are like from the inside. Veridical perceptual experiences, for instance, are not sensititve - and thus not phenomenally marked as being sensitive - to epistemic reasons because how they present things as being is determined by external objects and their perceivable features. Similarly, imaginative experiences and thoughts play no role in the motivation and justification of judgements and beliefs (other than introspective ones) precisely because they are determined by practical reasons (or perhaps also some non-rational causes). ${ }^{41}$

To sum up, both rational role and determination are prominent attitudinal aspects of the phenomenal character of judgemental thoughts and other mental episodes. This shows that what mental episodes are like from the inside is not exhausted by their presentation of objects as being a certain way. In other words, some aspects of phenomenal character pertain to attitude or commitment, rather than to content. The debate about whether thoughts possess a phenomenal character should therefore address not only the issue of whether it makes a phenomenal difference which concepts or propositions are involved in thinking, but also the issue of whether it makes a phenomenal difference whether the thoughts concerned are judgemental, imaginative, and so on.

Central to the discussion of the last issue is whether differences in rational role and determination are part of what thoughts are like from the inside. The arguments that I presented in sections 2 and 3 indicate that we should endorse Phenomenal Rationalism, which affirms the phenomenological salience of rational role. In particular, judgemental thoughts are phenomenally marked as having the rational role described by (SENS), (BASE) and (PROV) (at least if they are not self-justifying). But it is arguably also phenomenologically salient which particular proposition(s) the rational role of a given judgemental thought is concerned with - and, hence, which particular content the thought possesses. A crucial step in my line of reasoning to this conclusion has been the defense of the additional claim that the phenomenal character of mental epiodes - including that of judgemental thoughts - reflects the way how the episodes concerned are determined in cases where everything goes well. Indeed, this phenomenal impression of determination is essential to our related phenomenal awareness of rational role, irrespective of whether the mental episodes concerned are experiences or thoughts.

\section{Acknowledgements}

For comments on earlier drafts and related discussions, I am very grateful to Davor Bodrozic, 
Berit Brogaard, Elijah Chudnoff, Julien Dutant, Lucy O’Brien, Adrian Haddock, Anders Nes, Declan Smithies, Gianfranco Soldati, Matthew Soteriou, Gian-Andri Toendury, and two anonymous referees. I would also like to thank the editors, Marta Jorba and Dermot Moran, for giving me the opportunity to be part of this special issue. My research on this chapter was generously funded by the Swiss National Science Foundation (PP00P1_139004) and the Fundación Séneca (18958/JLI/13).

\section{Notes on contributor}

Fabian Dorsch is SNSF Research Professor at the University of Fribourg (Switzerland). He is author of The Nature of Colours (de Gruyter 2009), The Unity of Imagining (de Gruyter 2012) and the forthcoming Imagination (Routledge 2017) and has published articles on various topics in the philosophy of mind, epistemology, metaphysics, aesthetics, and the philosophy of normativity. He founded the European Society for Aesthetics and is editor of the journal Estetika - The Central European Journal of Aesthetics.

\section{References}

Armstrong, D. M. 1993. A Materialist Theory of the Mind. Rev. ed. London: Routledge.

Bayne, Tim, and Michelle Montague, eds. 2011. Cognitive Phenomenology. Oxford: Oxford University Press.

Budd, Malcolm. 1992. "Review of "Mimesis as Make-Believe: On the Foundations of the Representational Arts" by Kendall L. Walton.” Mind 101: 195-98.

Burge, Tyler. 1996. "Our Entitlement to Self-Knowledge." Proceedings of the Aristotelian Society 96: 91-116.

Burge, Tyler. 1998. "Reason and the First Person." In Knowing Our Own Minds, edited by Crispin Wright, Barry C. Smith, and Cynthia Macdonald, 243-70. Oxford: Oxford University Press.

Burge, Tyler. 2003. "Perceptual Entitlement." Philosophy and Phenomenological Research 67 (3): 503-48.

Carruthers, Peter. 2000. Phenomenal Consciousness. A Naturalistic Theory. Cambridge: Cambridge University Press.

Carruthers, Peter, and Benedicte Veillet. 2011. "The Case Against Cognitive Phenomenology." In Cognitive Phenomenology, edited by Timothy Bayne and Michelle Montague, 35-56. Oxford: Oxford University Press.

Crane, Tim. 2009. "Is Perception a Propositional Attitude?" The Philosophical Quarterly 59 (236): 452-69.

Dorsch, Fabian. 2009a. "Judging and the Scope of Mental Agency." In Mental Actions, edited by Lucy O'Brien and Matthew Soteriou, 38-71. Oxford: Oxford University Press.

Dorsch, Fabian. 2009b. Die Natur Der Farben. Berlin: De Gruyter.

Dorsch, Fabian. 2010a. "The Unity of Hallucinations." Phenomenology and the Cognitive Sciences 9 (2): 171-91.

Dorsch, Fabian. 2010b. "Transparency and Imagining Seeing." Philosophical Explorations 13 
(3): 173-200.

Dorsch, Fabian. 2011. Experience and Reason. Lausanne: Rero Doc.

Dorsch, Fabian. 2012. The Unity of Imagining. Berlin: De Gruyter.

Dorsch, Fabian. 2013. "Experience and Introspection." In Hallucination, edited by Fiona Macpherson and Dimitris Platchias, 175-220. Cambridge (Mass.): MIT Press.

Dorsch, Fabian. 2016a. "Knowledge by Visualisation -- How Imaginative Experiences Can Ground Factual Knowledge". Teorema, forthcoming.

Dorsch, Fabian. 2016b. "Perceptual Acquaintance and the Seeming Relationality of Hallucinations." Journal of Consciousness Studies, forthcoming.

Dorsch, Fabian. 2017a. "The Phenomenal Presence of Reasons." In Phenomenal Presence, edited by Fiona Macpherson, Martine Nida-Ruemelin, and Fabian Dorsch. Oxford: Oxford University Press.

Dorsch, Fabian. 2017b. Imagination. London: Routledge.

Goldman, Alvin, and Bob Beddor. 2015. "Reliabilist Epistemology." Edited by Edward N. $\mathrm{Z}$ a $1 \mathrm{ta}$. Stanford Encyclopedia of Philosophy (2015 Winter Edition). http:/plato.stanford.edu/archives/spr2011/entries/reliabilism/.

Harman, Gilbert. 1990. “The Intrinsic Quality of Experience.” In Collection, 4:31-52.

Hopkins, Robert. 1998. Picture, Image and Experience. Cambridge: Cambridge University Press.

Hopkins, Robert. 2011. "Imagination and Observation.” Unpublished manuscript.

Horgan, Terry, and John Tienson. 2002. "The Intentionality of Phenomenology and the Phenomenology of Intentionality." In Philosophy of Mind: Classical and Contemporary Readings, edited by D. Chalmers. Oxford: Oxford University Press.

Horgan, Terry, and Mark Timmons. 2007. "Moorean Moral Phenomenology." In Themes from G. E. Moore, edited by Susana Nuccetelli and Gary Seay, 203-26. Oxford: Oxford Univ Press.

Hume, David. 2007. A Treatise of Human Nature: A Critical Edition. Edited by David Fate Norton and Mary J Norton. Oxford: Clarendon Press.

Husserl, Edmund. (1901) 1984. Logische Untersuchungen. Den Haag: Nijhoff.

Kolodny, Niko. 2005. "Why Be Rational?” Mind 114: 509-63.

Kolodny, Niko. 2007. "How Does Coherence Matter?" Proceedings of the Aristotelian Society 107 (1): 229-63.

Kriegel, Uriah. 2015. The Varieties of Consciousness. Oxford: Oxford University Press. Lycan, William G. 1996. Consciousness and Experience. Cambridge, MA: MIT Press.

Martin, M. G. F. 1997. “Self-Observation.” European Journal of Philosophy 5 (2): 119-40.

Martin, M. G. F. 2000a. “An Eye Directed Outward.” In Knowing Our Own Minds, edited by Cynthia Macdonald, Barry C. Smith, and Crispin Wright, 99-123. Oxford: Oxford University Press.

Martin, M. G. F. 2000b. "Beyond Dispute: Sense-Data, Intentionality, and the Mind-Body Problem." In History of the Mind-Body Problem, edited by Tim Crane and Sarah Patterson, 195231. Routledge.

Martin, M. G. F. 2002. "The Transparency of Experience.” Mind and Language 17 (4): 376425.

Martin, M. G. F. 2004a. “Uncovering Appearances.” Oxford: Oxford University Press.

Martin, M. G. F. 2004b. "The Limits of Self-Awareness.” Philosophical Studies 120: 37-89. 
Martin, M. G. F. 2006. “On Being Alienated.” In Perceptual Experience, edited by Tamar Gendler and John Hawthorne, 354-410. Oxford: Oxford University Press.

McDowell, John. 1998. "Values and Secondary Qualities." In Mind, Value, and Reality, 11029. Cambridge (Mass.): Harvard University Press.

McHugh, Conor. 2012. "Reasons and Self-Knowledge." In The Self and Self-Knowledge, edited by Annalisa Coliva. Oxford: Oxford University Press.

Nagel, Thomas. 1974. "What Is It Like to Be a Bat?" The Philosophical Review 83: 435-50.

Owens, David. 2000. Reason Without Freedom: The Problem of Epistemic Normativity. London: Routledge.

O’Brien, Lucy. 2003. “On Knowing One's Own Actions.” In Agency and Self-Awareness: Issues in Philosophy and Psychology, edited by Johannes Roessler and Naomi Eilan, 358-82. Oxford: Clarendon Press.

Peacocke, Christopher. 1992. A Study of Concepts. Cambridge (Mass.): MIT Press.

Peacocke, Christopher. 1996. "Entitlement, Self-Knowledge and Conceptual Redeployment." Proceedings of the Aristotelian Society.

Peacocke, Christopher. 1998. "Conscious Attitudes, Attention and Self-Knowledge." In Knowing Our Own Minds, edited by Crispin Wright, Barry C. Smith, and Cynthia Macdonald, 63-98. Oxford: Clarendon Press.

Peacocke, Christopher. 1999. Being Known. Oxford: Clarendon Press.

Peacocke, Christopher. 2012. "Conscious Events and Self-Ascriptions: Comments on Heal and O'Brien." In The Self and Self-Knowledge, edited by Annalisa Coliva. Oxford: Oxford University Press.

Pitt, David. 2004. "The Phenomenology of Cognition or What Is It Like to Think That P?" Philosophy and Phenomenological Research 69 (1): 1-36.

Sartre, Jean P. (1940) 2004. The Imaginary: A Phenomenological Psychology of the Imagination. London: Routledge.

Scanlon, Thomas. 2008. Moral Dimensions: Permissibility, Meaning, Blame. Cambridge, MA: Harvard University Press.

Shields, Christopher. 2011. "On Behalf of Cognitive Qualia.” In Cognitive Phenomenology, edited by Tim Bayne and Michelle Montague, 215-35. Oxford: Oxford University Press.

Shoemaker, Sidney. 1994. "Self-Knowledge and 'Inner Sense'." Philosophy and Phenomenological Research 54 (2): 249-314.

Siegel, Susanna. 2006. "Subject and Object in the Contents of Visual Experience." Philosophical Review 115 (3): 355-88.

Siegel, Susanna. 2008. "The Epistemic Conception of Hallucination." In Disjunctivism: Perception, Action, Knowledge, edited by Adrian Haddock and Fiona Macpherson. Oxford: Oxford University Press.

Siegel, Susanna. 2015. "The Contents of Perception." Edited by Edward N. Zalta. The Stanford Encyclopedia of Philosophy (Spring 2015 Edition). http://plato.stanford.edu/archives/spr2015/entries/perception-contents/.

Siewert, Charles P. 1998. The Significance of Consciousness. Princeton: Princeton University Press.

Smithies, Declan. 2011. "What Is the Role of Consciousness in Demonstrative Thought?:" Journal of Philosophy 108 (1): 5-34. 
Soldati, Gianfranco. 2009. “Transparenz Der Gefühle.” In Emotionen Interdisziplinär, edited by Barbara Merker. Paderborn: Mentis.

Soteriou, Matthew. 2009. "Mental Agency, Conscious Thinking, and Phenomenal Character." In Mental Actions, edited by Lucy O'Brien and Matthew Soteriou. Oxford: Oxford University Press.

Speaks, Jeff. 2009. "Transparency, Intentionalism, and the Nature of Perceptual Content." Philosophy and Phenomenological Research 79 (3): 539-73.

Travis, Charles. 2004. "The Silence of the Senses." Mind 113: 59-94.

Tye, Michael. 1995. Ten Problems of Consciousness. Cambridge (Mass.): MIT Press.

Velleman, David. 2000. The Possibility of Practical Reason. Oxford: Oxford University Press.

Walton, Kendall. 1990. Mimesis as Make-Believe. Harvard: Harvard University Press.

Williamson, Timothy. 1990. Identity and Discrimination. Oxford: Blackwell. 
* Email: fabian.dorsch@unifr.ch

1 See, for instance, Siewert (1998) and Pitt (2004) for optimism and Carruthers (2000) for pessimism about the existence of content-related cognitive phenomenology. Most of the contributions to Bayne and Montague (2011) continue this debate.

2 Some notable exceptions are Horgan and Tienson (2002), Horgan and Timmons (2007), Shields (2011) and Kriegel (2015, ch. 1). Note also that, in what follows, I use 'content' and 'attitude' in very wide senses. In particular, saying that a mental episode has a content is not meant to imply that it has correctness conditions (see Martin $(2002,382)$ for discussion). As a result, instances of perceptual acquaintance count as having a content in my sense since they present things as being a certain way - and despite the fact that their relationality deprives them from the possibility of being non-veridical. See Siegel (2015) for a narrower definition of 'content' in terms of correctness conditions, and Travis (2004), among others, for the claim that perceptual acquaintance does not involve content in this narrower sense. Similarly, talk of the attitude of a mental episode is not intended to entail that the episode in question has a propositional content or is a propositional attitude. According to my usage, even non-propositional and non-conceptual experiences may involve attitudes, such as the attitude of perceiving or the attitude of imagining. For example, perceptual experiences need not be identified with judgement-like propositional attitudes in order to claim that they purport to present parts of our actual surroundings (rather than merely possible or fictional situations) - as Husserl's idea of 'leibhaftiger Gegenwart' (manifest presence; Husserl [1901] 1984, B 441f.) and Sartre's idea of perceptions as '[positing their] object as existing' illustrate (Sartre [1940] 2004, 12).

3 By which I mean experiences linked to one of the five outer senses, such as episodes of visual (auditory, tactile, etc.) perceiving, hallucinating, recalling or imagining. Whether similar considerations apply to bodily sensations, emotional feelings, moods or other kinds of non-intellectual episodes or 'experiences' is a further issue that needs to be addressed separately, as pointed out by one of the referees.

4 At least not intrinsically or by themselves (Dorsch 2012, ch. 2).

5 See Dorsch (2012, ch. 4) and Dorsch (2016a) for discussions of a notable exception, namely instances of visualising meant, and able, to ground knowledge.

6 I assume here that beliefs and semantic memories become occurrent, or manifest in consciousness, in the shape of thoughts with a judgemental attitude, that is, an attitude of taking the respective proposition to be true for the sake of, or with the aim of, getting it right (Velleman 2000, chs. 5 and 11). But, of course, not all judgemental thoughts are manifestations of already existing beliefs or semantic memories.

7 A good example among very many is the critical discussion of cognitive phenomenology in Carruthers and Veillet (2011).

8 Among the possible distinctions are: the sensory vs. the intellectual; the objectual vs. the propositional; the unstructured vs. the structured; the non-conceptual vs. the conceptual; the merely causal vs. the rational; or the non-cognitive vs. the cognitive.

9 The locus classicus is Nagel (1974). But see also the very helpful discussions in Williamson (1990) and Martin (2004a, ch. 2).

10 Introspection is understood here simply as the special form of access that we - and only we - enjoy to our own conscious mental episodes from our first-person (or subjective) perspective, and by means of which we are capable of forming higher-order judgements and beliefs about those episodes. Introspection is thus contrasted with third-person ways of acquiring knowledge about the conscious mind, such as observing the behaviour, speech and bodily expression of people, or studying their brains with the help of experiments and machines. But it is left open what the concrete nature of introspection is - for instance, whether it is a 'reflective act of consciousness' revealing what is certain about the conscous mind (Sartre [1940] 2004, 4), say, or just 'a self-scanning process in the brain' that may go wrong (Armstrong 1993, 324). Similar considerations apply to phenomenal character. By characterising it epistemologically as being identical with those aspects of mental episodes, that are accessible to us from our first-person perspective, I do not intend to presuppose any particular view about the nature of those aspects (e.g. how they are related to features of the brain) or of our phenomenal awareness of them (e.g. whether it is reflexive, objectual, higher-order, and so on).

11 The discussion here is meant to stay neutral on whether the reasons provided are identical with the mental episodes themselves, or rather with the (seeming) facts that they make us aware of.

12 Note that the term 'judgement' is ambiguous (Soteriou 2009). It may refer either to the instantaneous act of judging (or of triggering the occurrence in consciousness of an already existing belief or semantic memory), which constitutes the onset of an episode of entertaining a proposition with a judgemental attitude; or to the resulting judgemental episode of entertaining, namely a temporally extended judgemental thought (or occurrent belief or semantic memory). If not otherwise noted, when I speak of 'judgements', I have episodic judgemental thoughts in mind.

13 See Dorsch $(2009 \mathrm{a}, 2017 \mathrm{a})$ for further discussion of what it means for the rational role of mental episodes to be phenomenologically salient; and Owens (2000), Scanlon (2008) and Kolodny $(2005,2007)$ for detailed descriptions of the nature and first-person character of reasons and our responses to them.

14 Note that conformity to (SENS) does not require that judgements are responsive to reasons other than those provided by 
themselves. In particular, self-justifying judgements can count as responsive to reasons even though their justification cannot be defeated by any external or new evidence. Being based on self-provided reasons is already sufficient for being responsive to (some) reasons.

15 In what follows, I ignore how the warranted application of the concepts 'I' and 'judgemental thought' should be explained. But I suggest elsewhere (Dorsch 2011, Introduction) that they are also grounded in phenomenal awareness.

16 Armstrong (1993) and Lycan (1996) are among the proponents of the causal-reliabilist model of introspection.

17 See Martin (2000a, 2006) and Dorsch (2013). By contrast, our knowledge of how perceptual experiences - and thus also perceptual judgements - are caused enables us to formulate normal conditions for them (Dorsch 2009b, ch. 3.3).

18 It is unclear whether Peacocke (at least in his earlier writings) endorses the Prompting Model. In Dorsch (2009a), I read his view as such. But McHugh (2012) argues that Peacocke's - as well as his own - view goes beyond the Prompting Model, and Peacocke (2012, footnote 1) seems to acknowledge that this is the correct interpretation of what he believes. In any case, it is possible that a proponent of the Prompting Model follows Peacocke in taking the link between the lower- and the higher-order states to be neither constitutive, nor merely causal, but instead rational.

19 McHugh (2012) puts forward an alternative version of the Awareness Model, which maintains that the non-conceptual awareness in question is not phenomenal, but practical in nature. It is, however, unclear what this practical awareness is meant to amount to, or how it can underwrite and lead - via abstraction and conceptualisation - to theoretical higherorder judgements. In addition, it is unclear why McHugh resists taking the awareness of the reasonableness of judgemental thoughts (or perceptions) to be part of their phenomenal character, especially since it is difficult to see how he could otherwise account for the phenomenal difference between judgemental and imaginative thoughts (as well as perceptual and imaginative experiences). See also Dorsch $(2009 \mathrm{a})$ and Dorsch $(2012,13)$ for discussions of these phenomenal differences.

20 See Williamson (1990, ch. 4), Martin (2000b, 2004b, 2006) and Dorsch (2010b, 2013) for discussions of why it is not only unproblematic, but in fact very plausible to assume that phenomenal awareness can be misleading.

21 In Dorsch (2009a), I discuss how the phenomenal awareness of responsiveness to epistemic reasons differs from the phenomenal awareness of responsiveness to practical reasons, which pertains, for instance, to conscious (mental) agency.

22 See Dorsch (2009a, 50f.) and Dorsch (2011, Introduction) for further discussions. There, I also discuss that the phenomenal awareness in question is fallible and does not presuppose the possession of concepts like 'I', 'reason' or 'judgement', allowing that small children and perhaps even higher animals can enjoy it, too.

23 The underlying idea is that the possession conditions of concepts like 'reasonable' include a clause stating that rational subjects feel rationally compelled to employ the concept if they are phenomenally aware of the reasonableness of one of their thoughts and consider the issue of whether their thought is reasonable. See Peacocke (1992) for a general theory of concept possession along these lines, and McHugh (2012) for a discussion of the non-conceptuality of the awareness concerned (although he takes it to be practical rather than phenomenal).

24 This statement - as well as the corresponding one further below about the phenomenological salience of this determination relation - needs perhaps to be qualified. For other factors - such as the subject's attention, interests, past experiences or training - might, too, influence how veridical perceptions present things as being (I am grateful to one of the referees for raising this point). But it should be clear that the impact of such additional factors can at best be limited. First of all, they can influence only which of those properties, that the object in question in fact has, it is experienced as having (e.g. which of them the subject attends to or is sensitive towards). Otherwise, the resulting experiences would not be veridical anymore. Then, at least some of these factors may enjoy only some indirect impact on how we experience things, namely by determining which perceivable response-dependent properties the objects possess, and thus can be seen, in the first place. This may be the case, for instance, with attention-dependent Gestalt properties, or with certain 'artificial' functional properties (e.g. something may become a table because we start to see it as a table in response to our need for a table). Finally, even if our interests or past experiences let us focus on some perceivable properties of the objects rather than others, this does not amount to a case of practical (i.e. non-epistemic) determination, where how we experience things as being is a matter of what we want, or of which practical reasons are available to us (as, say, in the case of imagining).

Independently of this, it is worthwhile pointing out that the determination of veridical perceptions by their objects might extend beyond the qualities that we experience the objects as having. For perhaps the numerical identity of the veridical experiences depends on the numerical identity of the objects experienced, so that veridical perceptions of distinct blue books, say, differ even if we are not aware of any qualitatively differences between the books or, in fact, the experiences themselves (see, for instance, Martin 2002, and Dorsch 2016b). But nothing in what follows depends on whether veridical perceptual experiences are indeed relational in this strong sense.

25 It is important to note that what matters is that the experience concerned is conscious (Smithies 2011). We might also have subpersonal mental representations, the content of which is determined by how the world is like. But these would not put us into an equally good epistemic position as our conscious experience (if they would put us in a position to acquire knowledge, or form justified beliefs, about the external world at all) precisely because they are non-conscious 
and thus do not have any bearing on our rational, personal deliberations about what to believe.

One referee has pointed out to me that we are in an even better epistemic position if, in addition to our conscious veridical perception, we also know that it is a veridical perception (rather than an indistinguishable hallucination). This is true and captured by my view since it assumes that veridical perceptions (as well as hallucinations) are phenomenally marked as being veridical, meaning that enjoying a conscious veridical perception implies being in a position to come to know that it is veridical (see the next paragraph). That is, under normal conditions, we acquire knowledge when we endorse in belief the phenomenal impression of veridicality that comes with undergoing a veridical perception.

26 See Martin (2004b, 2006), Siegel (2008) and Dorsch (2010a, 2013) for more detailed discussions. Dorsch (2010a) locates the observation about the phenomenological salience of the determination of perceptual experiences by their objects in the broader context of providing a comprehensive description of their phenomenal character.

27 Some relationalists about perception deny that non-veridical perceptual experiences possess the same phenomenal character as veridical ones (e.g. Martin 2002, 2004b, 2006). But they agree that the two kinds of experience still resemble each other in what they are like for the subject. More specifically, non-veridical experiences possess a phenomenal character that is introspectively indistinguishable from the phenomenal character of veridical experiences. See Dorsch (2016b) for discussion.

28 This is a fairly minimal characterisation of the transparency of experience, which is compatible with the idea that introspective reflection also reveals certain features of the experiences themselves, such as their rational role or determination (Martin 2002). Some philosophers add the claim that we do not come to notice anything but the objects of experience and their features. This implies, in particular, that we cannot become attentively aware of aspects of our experiences other than what they present us with.

29 See also Harman (1990) and Speaks (2009), among many others. One of the few dissenting voices is Hume (2007, sec. 1.4.2) who - as discussed in Martin (2000b) - believed that the phenomenal character of our perceptual experiences is neutral on whether they make us aware of external or internal objects. But there is, of course, the doubt that his belief was more influenced by this theoretical convictions concerning sense-data than by his introspective reflections about his own perceptual experiences.

30 This expectation is especially pronounced because (though does not necessarily require that) the objects of our perceptual experiences seem to us to be external. Assuming that the objects are not dependent on our experiences, the two kinds of entity would be completely unrelated to each other if our experiences were also not dependent on their objects (or, at least, on their perceivable properties). Hence, the fact that we do take our perceptual experiences to be intimately linked to their experience-independent objects reveals that these objects seem, from the inside, to be determinants of our experiences.

31 Or at least not in a direct manner. We may of course act on our intention to visualise something as having exactly the same colour and shape as the book that we see in front of us. But, in this case, the direct determinant of our imaginative experience is our intention, and not (our perception of) the external book. See Dorsch (2009a) and Dorsch (2017b, pt. 2) for discussion.

32 The formulation chosen in the main text leaves open the possibility that imaginative experiences might also sometimes appear to occur in a spontaneous and seemingly arbitrary way, or as the causal effects of some non-rational factors. But, in Dorsch (2012, ch. 13f.), I argue at length that imagining is always an instance of mental agency, and that spontaneously or otherwise causally occurring imaginative experiences or thoughts belong to a third category of mental episodes. I discuss the various option of how imaginative experiences and thoughts might be said to be determined in Dorsch (2017b, pt. 2).

33 The main exception are trivial inferences of the form 'if $p$ and $q$, then $p$ '. Besides, I ignore here that judgemental thoughts may perhaps also provide reasons for introspective judgements (see the discussion of Peacocke's position in section 2).

34 See Dorsch (2016a) for more on the two aspects of rational determination and, especially, their relative independence.

35 I ignore here that the underlying perceptions or beliefs might have to be veridical or true in a non-accidental manner as well in order for the resulting judgements to count as knowledgeable.

36 Again, if someone endorses a form of disjunctivism (or non-conjunctivism) which denies that knowledgeable and nonknowledgeable judgemental thoughts possess the same phenomenal character, the claim will rather be that nonknowledgeable judgemental thoughts possess a character that is introspectively indistinguishable from (though not identical with) the character of knowledgeable judgemental thoughts.

37 See Hopkins (2011) and Dorsch (2017b, ch. 4). The considerations that follow in the next paragraph might still be read as suggesting that judgemental thoughts are transparent to the sufficiency of the epistemic reasons on which they are based, even though they are not transparent to the identity of those reasons.

38 This line of reasoning was suggested to me by one of the anonymous referees.

39 See, for instance, the references to Husserl's and Sartre's writings in endnote 2, as well as Martin's idea of the 'immediacy' of perception (Martin 2002) and the discussion of Husserl's view in Soldati (2009). I provide a detailed description of the phenomenology of perceptual, mnemonic and imaginative experiences in Dorsch (2010a). 
40 Although it should be kept in mind that they do not involve an instance of visualising, nor are a fusion of seeing and visualising (Budd 1992; Hopkins 1998, ch. 1).

41 This is not completely true. With respect to the rational determination of propositional content, certain episodes of visualising can ground knowledge in the same way as perceptual experiences. But the imaginative experiences concerned need the help of higher-order judgements about their non-accidental veridicality in order to give rise to an attitude of belief rather than an attitude of imagining. See Dorsch (2012 ch. 4) and Dorsch (2016a) for detailed discussions. 